\title{
Sensitive and Critical Periods for Visual Calibration of Sound Localization by Barn Owls
}

\author{
Eric I. Knudsen and Phyllis F. Knudsen \\ Department of Neurobiology, Stanford University School of Medicine, Stanford, California 94305-5401
}

This study describes developmental changes in the capacity of owls to adjust sound localization in response to chronic prismatic displacement of the visual field and to recover accurate sound localization following the restoration of normal vision. Matched, binocular displacing prisms were mounted over the eyes of 19 barn owls (Tyto alba) beginning at ages ranging from 10 to $272 \mathrm{~d}$. In nearly all cases, the visual field was shifted $23^{\circ}$ to the right. Sound localization was assessed on the basis of head orientations to sound sources, measured in a darkened sound chamber with a search coil system.

Chronic exposure to a displaced visual field caused the owls to alter sound localization in the direction of the visual field displacement, thereby inducing a sound-localization error. The size of the sound-localization error that resulted depended on the age of the animal when prism experience began. Maximal errors of about $20^{\circ}$ were induced only when prism experience began by $21 \mathrm{~d}$ of age. As prism experience began at later ages, the magnitude of induced errors decreased. A bird that wore prisms beginning at $102 \mathrm{~d}$ of age, altered sound localization by only $6^{\circ}$. An adult owl, when exposed chronically to a displaced visual field, altered sound localization by about $3^{\circ}$. We refer to the early period in life when displaced vision induces exceptionally large soundlocalization errors (relative to those induced in the adult) as a sensitive period.

The capacity to recover accurate sound localization following restoration of normal vision was tested in 7 owls that had been raised wearing prisms. Four owls that had prisms removed by $182 \mathrm{~d}$ of age recovered accurate localization rapidly (over a period of weeks), whereas 3 owls that were older when the prisms were removed did not recover accurate localization when tested for up to 7 months after prism removal. Adjustment of sound localization slowed greatly or ceased at about $\mathbf{2 0 0}$ days of age, referred to here as the critical period for visual calibration of sound localization.

Three owls were subjected repetitively to displacement of the visual field. An owl that adjusted sound localization to the left of normal during the sensitive period retained the capacity to adjust again to the left, but not to the right of normal, later in the critical period. The converse was true for

\footnotetext{
Received Apr. 3, 1989; revised July 27, 1989; accepted July 31, 1989.

We thank M. Brainard, S. Esterly, A. Ghosh, M. Konishi, and C. Shatz for comments on the manuscript. This work was supported by a grant from the National Institutes of Health (R01 NS16099-09).

Correspondence should be addressed to Eric I. Knudsen, Ph.D., at the above address.

Copyright (C) 1990 Society for Neuroscience $0270-6474 / 90 / 010222-12 \$ 02.00 / 0$
}

an owl that adjusted sound localization to the right of normal during the sensitive period. This result indicates that (1) adjustments to the left and to the right of normal are regulated independently and (2) adjustment away from normal during the sensitive period preserves the capacity for adjustment in that same direction when the capacity otherwise would have been lost with the closing of the sensitive period. Our interpretation of this result is that experience during the sensitive period, together with an innate predisposition for normal localization, establish the range of possible adjustment states from which experience during the critical period selects the persistent state.

Vision controls the developement of sound-localization accuracy in barn owls (Knudsen and Knudsen, 1985, 1989b). Baby owls that view the world through displacing prisms from the first day the eyes open alter their sound localization to match their shifted visual worlds. When they hear an interesting stimulus, instead of orienting the head toward the source, as do normal owls, prism-reared owls orient to the side of the source by an amount that corresponds to the prismatic displacement of the visual field. This behavior is adapative in that it brings the source of a sound onto the areae centrali of the eyes so that the animal looks at the source. However, the owl mislocalizes the stimulus because it does not learn to reinterpret the position of the head relative to the body, as humans do so readily in response to displacing prisms (Held and Bossom, 1961; Harris, 1965). Instead, when a prism-reared owl approaches a stimulus source, it follows the orientation of the head and therefore misses to the side of the source (Knudsen and Knudsen, 1989a). Thus, even though interaction with the environment from the beginning of life has proven to owls that their visual perception of stimulus source location is inaccurate, they nevertheless use vision to calibrate sound localization, which in this case leads to a gross error in sound localization.

These observations indicate that the spatial meaning of auditory localization cues is learned from vision. Sound localization is based on the association of the values of auditory cues, such as interaural time differences (ITD) and interaural intensity differences (IID), with locations in space. The correspondence of a particular cue value (for example, ITD $=25 \mu \mathrm{sec}$ left ear leading at $4 \mathrm{kHz}$ ) with a direction in space depends on the size and shape of the head and ears. Therefore, these correspondences vary across individuals, and they vary for a given individual as it grows. Vision, by indicating precisely the locations of potential sound sources, instructs the association of cue values with locations so that they are appropriate for the individual (Knudsen and Knudsen, 1985, 1989b). Displacing prisms shift the projection of the visual world onto the retinae (the eyes of 
barn owls are virtually stationary in the head) and thereby shift the locations in visual space with which auditory localization cues must be associated in order to maintain mutually consistent auditory and visual spatial percepts of the environment.

Newborn owls adjust sound localization by up to $20^{\circ}$ in response to displaced vision (Knudsen and Knudsen, 1989b). In contrast, adult owls subjected to prisms adjust sound localization by only a few degrees (Knudsen and Knudsen, 1985). This suggests that the capacity for large-scale adjustments becomes restricted during ontogeny. This study confirms this suggestion and describes quantitatively the decline in adjustment capacity with age. We investigate the period in life when exposure to abnormal conditions leads to abnormal function, the sensitive period, by imposing displaced vision on owls at progressively later ages and measuring the size of the sound-localization error that results. We also investigate the period when exposure to normal conditions enables the development of normal function, which is termed the critical period, by restoring normal vision at progressively later ages to owls that have adjusted sound localization in response to prism-rearing and measuring their capacity to recover accurate localization.

The sensitive and critical periods for visual calibration of sound localization are found to follow different time courses. The sensitive period is characterized by a gradual decrease in the effect of displaced vision on sound localization that approaches adult levels by about $110 \mathrm{~d}$ of age, whereas the critical period ends relatively abruptly at about $200 \mathrm{~d}$ of age, beyond which adjustment of sound localization of any kind is severely restricted. Because of the different time courses and because of the way in which the capacity for adjustment changes as owls pass through these periods, we conclude that different neuronal mechanisms underlie the sensitive and the critical periods.

\section{Materials and Methods}

The techniques used in this study are described in detail in a previous report (Knudsen and Knudsen, 1989b). Data were collected from 19 barn owls (Tables 1-3). Matched binocular Fresncl displacing prisms (Vision Care/3M) were mounted chronically over the eyes beginning at ages ranging from 10 to $272 \mathrm{~d}$. The prisms were held in place with lightweight spectacle frames which were strapped to the head of owls younger than $30 \mathrm{~d}$ of age and were bolted to the skulls of older owls. The visual field was displaced to the right, except in owl 18 (Table 3). The prisms were aligned such that a collimated beam passed through either lens diffracted identically. Most of the owls experienced $23^{\circ}$ displacements (40 diopters), 2 owls experienced $11^{\circ}$ displacements $(20$ diopters), and 2 owls experienced $34^{\circ}$ displacements (60 diopters). The prisms afforded a wide field of view: in the worst case ( $34^{\circ}$ prisms), the azimuthal extent of the visual field was $60^{\circ}$ for the right eye and $80^{\circ}$ for the left eye. The optical properties of the prisms, the extent of the visual field afforded by the different prism strengths, and the effect of the prisms on sound reaching the cars arc described in Knudsen and Knudsen (1989b).

Owls $1-16$ (Tables 1,2 ) wore prisms continuously for a single period of time that ranged from 24 to $219 \mathrm{~d}$. Owls 17-19 (Table 3 ) experienced 2 or 3 separate periods of displaced vision: for owl 17 , the displacement was repeatedly to the right; for owls 18 and 19 , the direction of the displacement was alternated.

Experience. The owls were raised in communal cages where they were exposed to a rich environment of temporally correlated visual and auditory stimuli. They actively explored their cages and practiced pouncing on objects. They interacted vigorously with each other, vocalized frequently, and used vocalizations and vision to locate siblings. During the training and testing period, they were handled almost daily and were occasionally released in a large flight room for additional experience and excrcisc.

Test conditions. Sound-localization accuracy was quantified by comparing the way the owls oriented the head to auditory versus visual stimuli; a normal owl orients the head identically to both kinds of stimuli
(Knudsen et al., 1979). Behavioral tests were conducted with the owl perched in a darkened sound isolation chamber (IAC 404A). Auditory stimuli were generated by a movable $4 \mathrm{~cm}$ loudspeaker and consisted of repetitive noise bursts of variable amplitude, duration, and repetition rate. Visual stimuli consisted of a modulated glow from a light-emitting diode that was centered in the speaker cone. The loudspeaker and photodiode were attached to a semicircular track that moved around the owl by remote control (Knudsen and Knudsen, 1989b).

Head orientations were monitored using a search coil system (C-N-C Engineering). The induction coils were $1.8 \mathrm{~m}$ in diameter. A search coil was attached to the head by a clip cemented to the skull. The search coil system was calibrated before each test session. The precision of the system was $\pm 0.1^{\circ}$ in the frontal area that was sampled most heavily (angles less than $30^{\circ}$ from $0^{\circ}$ azimuth, $0^{\circ}$ elevation) and fell to about $\pm 1.0^{\circ}$ at the most extreme positions used.

Test paradigm. The owl was placed on a perch in the center of the sound chamber. The search coil was attached to the head and the lights were extinguished. The loudspeaker/photodiode was moved to a random location in front of the owl. Then, either the auditory or the visual stimulus was presented for $2 \mathrm{sec}$, which was long enough to allow the owl to make several movements to maximize the accuracy of its orientation response. If the animal did not respond, the stimulus was turned off and a waiting period of about $30 \mathrm{sec}$ ensued. Typically, however, the animal responded immediately with a quick head movement and a sustaincd fixation. The coordinates of the orientation response were recorded, a reward light was activated, and a food reward delivered. The reward criteria were that the owl turn its head crisply and fixate on a point during the stimulus. After every trial, the stimulus source was moved to a new, random location. Because auditory and visual stimuli were presented independently and because the accuracy of head orientation relative to the target was not a criterion for reward, the test paradigm assessed the effect that experience outside of the test chamber had on orientation to sensory stimuli and did not itself modify that behavior.

Quantification of sound localization. Accuracy is defined as the closeness of localization responses to the true location of the sound source; precision is defined as the consistency of the responses. A test session consisted of 10-25 responses to the auditory stimulus and a similar number of responses to the visual stimulus. Each response was quantified as the search coil reading minus the position of the stimulus source to yield coil orientation relative to source location. Mean response and standard deviation were calculated separately for the auditory and visual responses. The difference between the mean auditory and the mean visual response is reported as the auditory-visual (Aud-Vis) difference, and it indicates the degree to which auditory and visual localization were congruent. The actual orientation of the head relative to the stimulus source is given by the mean head orientation. Calculation of mean head orientation required knowledge about the orientation of the search coil relative to the head ("coil error"). Because both normal and prismreared owls orient the head directly at visual stimuli when they are not wearing prisms (Knudsen and Knudsen, 1989b), coil error was measured as the mean visual response for all orientations made without prisms. Search coil error was calculated for each bird after all measurements were completed. Mean head orientation relative to the stimulus source was derived by subtracting the coil error from the mean auditory and mean visual responses for each day. Sound-localization accuracy was quantified as the mean head orientation relative to the auditory stimulus: note that for a bird not wearing prisms, mean head orientation to auditory stimuli is equal to the Aud-V is difference. The precision of sound localization was quantified as the standard deviation of the responses to the auditory stimulus on each day.

\section{Results}

Results are presented in 4 sections. The first section discusses observations made during the period when owls were wearing prisms for the first time. The second section demonstrates the effect of age on the magnitude of change in sound localization induced by prisms. The third section describes the effect of age on the capacity for recovering accurate localization when normal experience is restored by removing the prisms. The fourth section describes how adjustment of sound localization early in development alters the capacity for adjustment later in the critical period. 


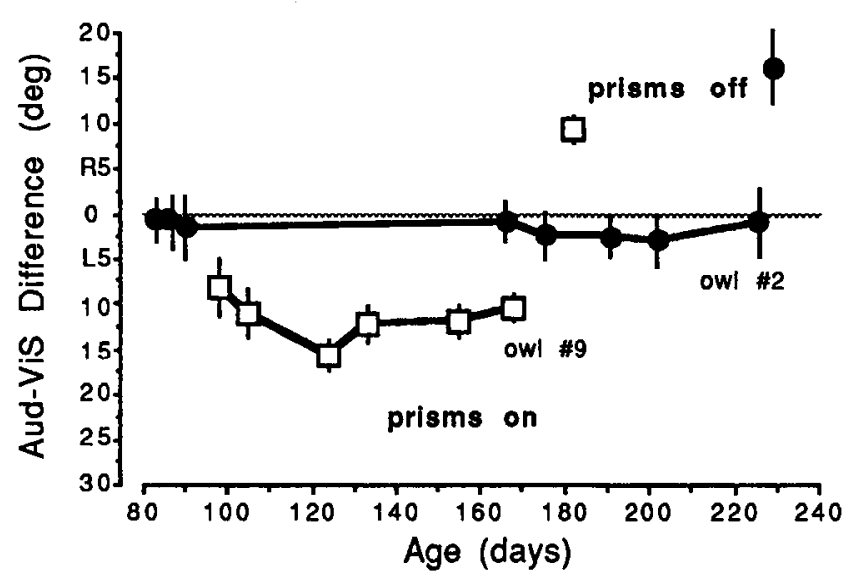

Figure 1. Auditory localization relative to visual localization with and without prisms. The azimuthal components of Aud-Vis differences for owls 2 (circles) and 9 (squares) are plotted as a function of age. Owl 2 wore $23^{\circ}$ right-displacing prisms from 10 to $229 \mathrm{~d}$ old; owl 9 wore $23^{\circ}$ right-displacing prisms from 63 to $182 \mathrm{~d}$ old. Error bars indicate the $\mathrm{SD}$ of auditory localizations. Although owl 9 continued to experience an auditory-visual discrepancy in localization, no systematic adjustment of sound localization occurred after measurements began. The magnitude of the sound localization error that was induced in each bird is indicated by the Aud-Vis difference after prism removal.

\section{Initial adjustment to displaced vision}

The effect of experience with displacing prisms on sound localization accuracy could not be assessed quantitatively until the birds were old enough to stand on a perch and perform the behavioral paradigm (see Materials and Methods); the earliest age at which a full set of data was collected was $60 \mathrm{~d}$ old. Of the owls that received prisms before $80 \mathrm{~d}$ of age (owls 1-10; Table 1), none was tested sooner than $23 \mathrm{~d}$ after prism attach- ment. All of these owls had finished adjusting sound-localization accuracy before the first measurements were made: Aud-Vis differences showed no systematic change during periods of up to 6 months of prism experience. The Aud-Vis differences recorded for owls 2 and 9 while they wore prisms are plotted as a function of age in Figure 1. In the case of owl 9, although a substantial discrepancy in auditory and visual localization existed, no further adjustment of sound localization was apparent. Thus, we have no quantitative data on the initial adjustment process, except that it could be finished in less than $23 \mathrm{~d}$ of prism experience. The time course of initial sound-localization adjustment could not be ascertained from the data of owls that received prisms when they were older $(102,110$, and $272 \mathrm{~d}$ old), because they made so little adjustment.

Although the initial adjustment of sound localization was not followed quantitatively, localization behavior of baby owls was observed qualitatively. Birds as young as $14 \mathrm{~d}$ old oriented the head in the general direction of sound sources, indicating some capacity for sound localization. Head orientation to visual stimuli was elicted in some owls by $17 \mathrm{~d}$ of age. When prisms were mounted on owls at 10-15 d of age (owls 1-4), the prisms had no apparent effect on the direction of auditory responses at least until the owls were older than $25 \mathrm{~d}$; the owls always oriented the head toward the source of the sound. By $30 \mathrm{~d}$ of age, some responses to sound were directed to the right of the source, while others were still directed accurately. By $40 \mathrm{~d}$ of age, nearly all responses to sound were to the right of the source. However, the responsiveness of these baby owls to auditory and visual stimuli and the precision of their movements were substantially less than those of normally sighted siblings.

Measurements in older owls revealed that Aud-Vis differences of some of the birds that were wearing prisms fluctuated from day to day by amounts that were greater than the fluctuations observed in normal birds without prisms. Measurements from

Table 1. Barn owls subjected to prisms for one continuous period

\begin{tabular}{|c|c|c|c|c|c|c|c|c|c|c|}
\hline \multicolumn{2}{|l|}{ Owl } & \multirow{2}{*}{$\begin{array}{l}\text { Prism } \\
\text { strength } \\
\text { (deg. right) }\end{array}$} & \multirow{2}{*}{$\begin{array}{l}\text { Prisms } \\
\text { on } \\
\text { (age in } \\
\text { days) }\end{array}$} & \multirow{2}{*}{$\begin{array}{l}\text { Prisms } \\
\text { off } \\
\text { (age in } \\
\text { days) }\end{array}$} & \multicolumn{3}{|l|}{ Prisms on } & \multicolumn{3}{|l|}{ Prisms off } \\
\hline No. & Identity $^{a}$ & & & & $\begin{array}{l}\text { A-V difference } \\
\text { (deg.) }\end{array}$ & \pm & $\begin{array}{l}\text { auditory SD } \\
\text { (deg.) }\end{array}$ & $\begin{array}{l}\text { A-V difference } \\
\text { (deg.) }\end{array}$ & \pm & $\begin{array}{l}\text { auditory SD } \\
\text { (deg.) }\end{array}$ \\
\hline 1 & $\mathrm{Ol}$ & 23 & 10 & - & R 0.1 & \pm & 3.1 & - & \pm & \\
\hline 2 & Is & 23 & 10 & 229 & L 1.1 & \pm & 3.6 & R 16.0 & \pm & 5.8 \\
\hline 3 & Ro & 23 & 14 & 79 & L 1.1 & \pm & 2.6 & R 17.4 & \pm & 1.8 \\
\hline 4 & $\mathrm{Da}$ & 23 & 15 & 98 & R 0.1 & \pm & 1.7 & R 20.9 & \pm & 1.9 \\
\hline 5 & $\mathrm{Te}$ & 23 & 21 & 92 & L 3.2 & \pm & 2.4 & R 16.5 & \pm & 1.7 \\
\hline 6 & Ap & 23 & 25 & 100 & L 6.4 & \pm & 1.6 & R 11.9 & \pm & 2.0 \\
\hline 7 & Go & 23 & 35 & 140 & L 8.6 & \pm & 2.6 & R 11.2 & \pm & 2.5 \\
\hline 8 & $\mathrm{Wi}$ & 23 & 49 & 190 & L 10.5 & \pm & 1.3 & R 10.1 & \pm & 2.4 \\
\hline 9 & Or & 23 & 63 & 182 & L 10.4 & \pm & 1.5 & R 9.4 & \pm & 1.5 \\
\hline 10 & Ep & 23 & 77 & - & L 11.9 & \pm & 1.7 & - & \pm & \\
\hline 11 & Sh & 23 & 102 & 177 & L 16.3 & \pm & 2.2 & R 5.8 & \pm & 1.6 \\
\hline 12 & $\mathrm{Ha}$ & 23 & 272 & 334 & L 19.9 & \pm & 2.5 & R 2.4 & \pm & 1.6 \\
\hline 13 & $\mathrm{Pi}$ & 11 & 110 & 183 & L 7.3 & \pm & 2.0 & R 3.1 & \pm & 1.2 \\
\hline 14 & $\mathrm{Ma}$ & 11 & 12 & 103 & L 1.6 & \pm & 3.0 & R 9.4 & \pm & 2.0 \\
\hline 15 & $\mathrm{Fi}$ & 34 & 12 & 159 & L 12.3 & \pm & 4.6 & R 17.6 & \pm & 3.4 \\
\hline 16 & $\mathrm{Mi}$ & 34 & 12 & 214 & L 11.6 & \pm & 2.0 & R 17.1 & \pm & 2.1 \\
\hline
\end{tabular}

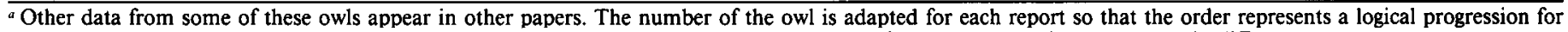
that study. The identity of the owl is maintained across papers to enable comparison of data from the same animal presented in different papers.

"Final measurement before prisms were removed.

c First measurement after prism removal. 


\section{PRISMS ON}

A

owl \#5

prisms on

at 21 days

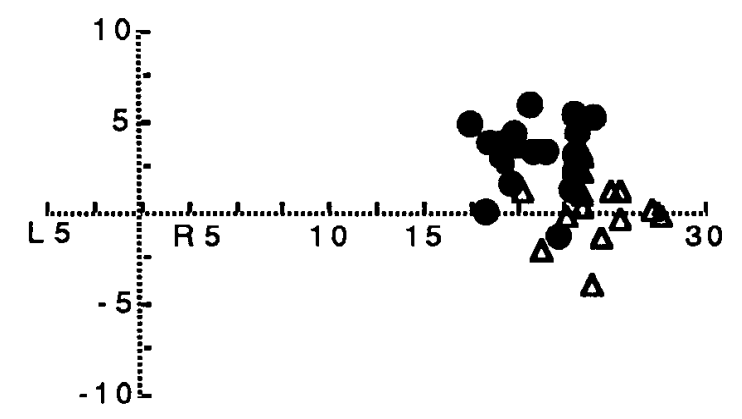

B

owl \#8

prisms on at 49 days

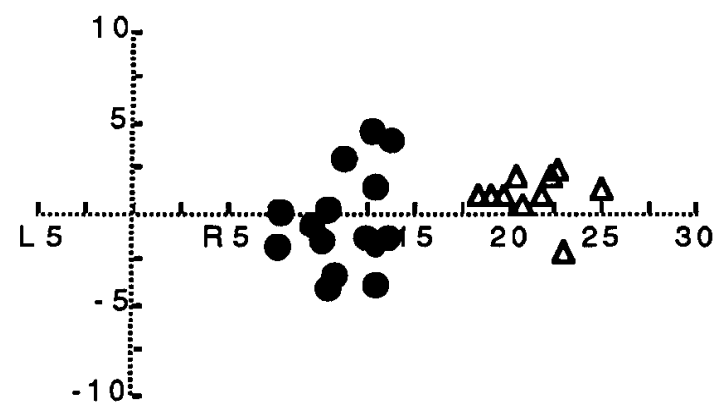

C

owl \#11

prisms on at 102 days

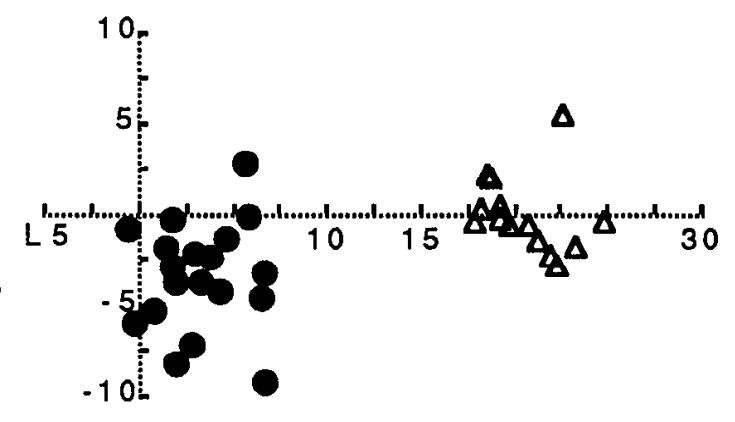

\section{PRISMS OFF}
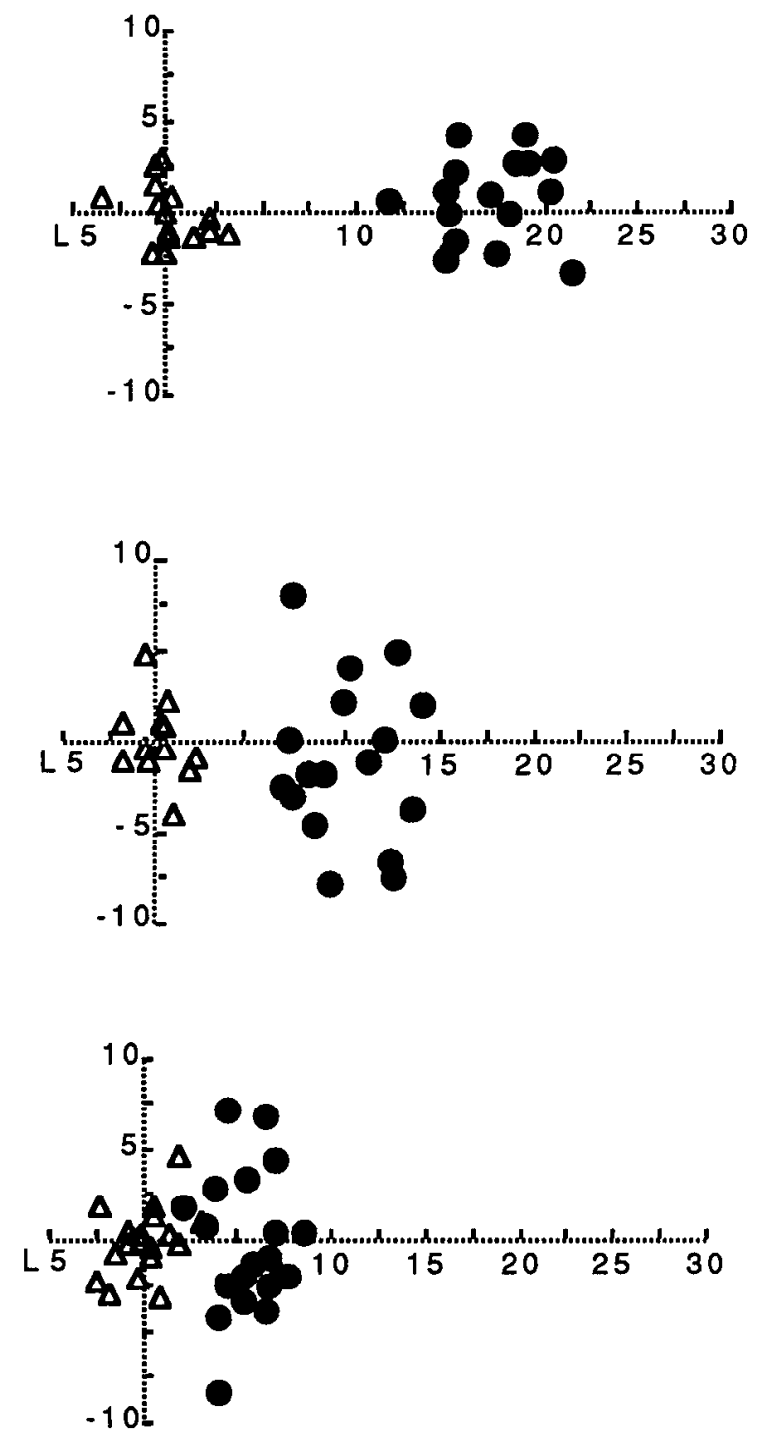

Figure 2. Orientations to auditory and to visual targets by prism-reared owls. Individual responses to auditory (closed circles) and to visual (open triangles) stimuli are plotted in coordinates of space relative to the location of the stimulus source; data at left were collected just before the prisms were removed; data at right were collected just after the prisms were removed. $A$, Owl 5 wore prisms from 21 to $92 \mathrm{~d}$ old. $B$, Owl 8 wore prisms from 49 to $190 \mathrm{~d}$ old. $C$, Owl 11 wore prisms from 102 to $177 \mathrm{~d}$ old.

an earlier study (Knudsen et al., 1984a) showed that fluctuations of Aud-Vis differences in 4 normal owls, each tested at least 6 times over periods of 2 months, ranged by $\pm 0.4^{\circ}$ to $\pm 1.1^{\circ}$ from a mean value. Of the 19 prism-reared owls in this study, the Aud-Vis differences of 12 ranged by less than $\pm 1.1^{\circ}$ during the period preceding prism removal, when sound localization was prcsumably stable. The Aud-Vis differences of the remaining 7 owls ranged by $\pm 1.2^{\circ}$ to $\pm 3.7^{\circ}$ from the mean value. The largest fluctuations in Aud-Vis differences $\left( \pm 3.7^{\circ}\right)$ are shown in Figure 1 (owl 9). Because of the uncertainty caused by such fluctuations, we feel that the most reliable estimate of the induced soundlocalization error is the Aud-Vis difference measured after the prisms were removed (Table 1). Prism removal eliminates any optical or acoustical effects caused by differences in the positioning, orientation, or quality of the prisms that may have contributed to these fluctuations.

\section{Sensitive period}

Figures 2 and 3 show the effect of subjecting owls to a displaced visual field at different ages. Owls $1-4$ wore prisms from the earliest ages (10-15 d old) and exhibited the largest soundlocalization errors: with the prisms on, they oriented the head as far to the right of auditory stimuli as they did to visual stimuli. For these owls, Aud-Vis differences were less than $2^{\circ}$ with the prisms on (Fig. $3 A$ ), indicating that they had adjusted sound localization to match the visual displacement induced by the prisms. Sound-localization errors of owls 2-4 after prism removal ranged from $\mathrm{R} 16.0^{\circ}$ to $\mathrm{R} 20.9^{\circ}$ (Fig. $3 B$; owl 1 was not measured with prisms removed).

Owls 5-10 experienced displaced visual fields beginning at 21 to $77 \mathrm{~d}$ old (Table 1). These owls also altered sound localization to the right, but the magnitude of the induced auditory error 
A

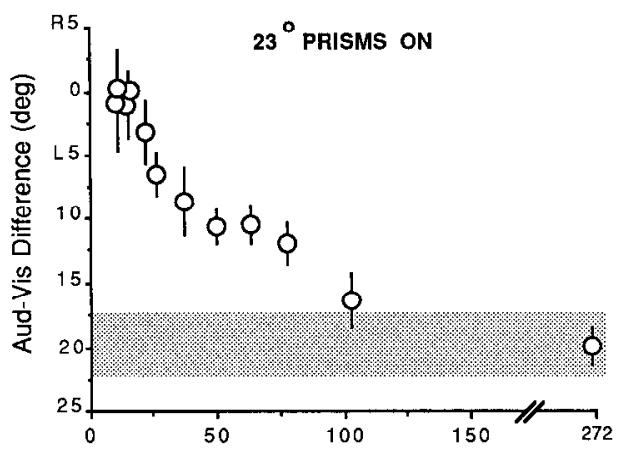

B

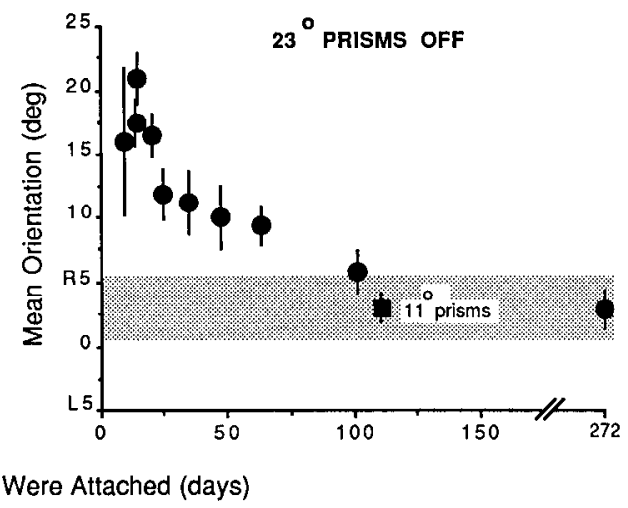

Figure 3. Sensitive period for adjusting sound localization in response to a displaced visual field. All owls experienced a $23^{\circ}$ rightward displacement except owl 13 (square), which experienced an $11^{\circ}$ rightward displacement. All of the owls had finished adjusting to the prisms by the time the data were collected. $A$, The azimuthal components of Aud-Vis differences measured on the final day before prism removal are plotted as a function of the age at which prism experience began. $B$, Mean head orientation to the auditory stimulus measured just after prism removal. Error bars indicate the SD of responses to auditory stimuli. The shaded area indicates 2 SD ( $95 \%$ confidence interval) from the mean value for the adult ( $272 \mathrm{~d}$ ) owl. The $95 \%$ confidence interval for the accuracy of normal adult owls ( 6 individuals; 22 test sessions) is $3^{\circ}$ (Knudsen and Knudsen, $1984 a$ ).

was smaller than that induced in owls $1-4$ (Fig. 3). Aud-Vis differences with the prisms on ranged from $\mathrm{L}^{\circ}$ to $\mathrm{L} 12^{\circ}$. The lack of complete adjustment of sound localization to match the prism-induced visual displacement was not due to inadequate time for adjustment, since Aud-Vis differences remained constant for months, as long as the prisms were worn (Fig. 1). Mean head orientation to the acoustic target mcasurcd immcdiatcly after prism removal confirmed that the magnitude of the induced sound-localization errors was smaller in owls that were subjected to prisms at older ages (Figs. 2, 3B). Localization errors decreased systematically from $\mathrm{R} 16.5^{\circ}$ in owl 5 , which received prisms at $21 \mathrm{~d}$ old, to $\mathrm{R} 9.4^{\circ}$ in owl 9 , which received prisms at $63 \mathrm{~d}$ old (owl 10 was not measured with prisms removed).

Owls 11 and 12 wore prisms beginning at 102 and $272 \mathrm{~d}$, respectively. Sound localization by these older birds was followed from the first day of prism experience. A decrease in AudVis differences during the more than 2 months of prism experience was not apparent because of day-to-day fluctuations in Aud-Vis differences. However, after removing the prisms, soundlocalization errors were R5. $8^{\circ}$ for owl 11 and R2.4 for owl 12 (Fig. 3B). Based on 22 test sessions with 6 normally reared owls (Knudsen et al., 1984a), the average accuracy of normal owls is $1.4^{\circ} \pm 0.8^{\circ}(\mathrm{SEM})$. Thus, owls 11 and 12 made little adjustment of sound localization in response to displaced vision.

To test whether larger adjustments could be induced in older owls when the auditory-visual discrepancy was less drastic, we placed weaker prisms (11 $1^{\circ}$ right displacements) on owl 13 when it was $110 \mathrm{~d}$ old, about the same age as owl 11 when it received $23^{\circ}$ prisms (Table 1). Although Aud-Vis differences decreased slightly during the first weeks of prism experience, the sound-localization error measured following prism removal after $72 \mathrm{~d}$ of prism experience was only R3.1 (square in Fig. $3 B$ ). This sound-localization error was about half as large as the $5.8^{\circ}$ error induced by $23^{\circ}$ prisms in owl 11 . In a previous study (Knudsen and Knudsen, 1989b), 2 owls subjected to $11^{\circ}$ prisms at 10 and $12 \mathrm{~d}$ of age, respectively, exhibited large sound-localization errors of $\mathrm{R} 7.5^{\circ}$ and $\mathrm{R} 9.4^{\circ}$ following prism removal. Thus, the decreasing capacity for adjustment of sound localiza- tion as a function of age is not a phenomenon that is specific to the strength of the prisms used.

The data demonstrate a sensitive period for the effect of displacement of the visual field on sound localization. The capacity for visually induced alterations in sound localization is greatest when abnormal experience begins by $21 \mathrm{~d}$ of age. The sensitive period does not end abruptly, but draws to a close gradually over the next $100 \mathrm{~d}$ of development. After the end of the sensitive period, a substantially reduced capacity to adjust to abnormally displaced vision persists into adulthood.

\section{Critical period}

In addition to being interested in the period of life when displaced vision induced errors in sound localization, we were interested in the age by which normal vision must be restored in order to recover normal sound-localization accuracy, i.e., the critical period. To determine the extent of the critical period, we removed prisms at systematically different ages from 7 owls that had adjusted sound localization in response to prism-rearing (Table 2). Four of the owls were from the group used to investigate the sensitive period: owls $2,7,8$, and 9 (Table 1). The other 3 owls $(14,15$, and 16; Table 2) were from a group used to investigate the limits of prism-induced shifts in sound localization (Knudsen and Knudsen, 1989b). Owl 14 was raised wearing $11^{\circ}$ right-displacing prisms; owls 15 and 16 were raised wearing $34^{\circ}$ right-displacing prisms.

Immediately following prism removal, the owls exhibited sound-localization errors of from $\mathrm{R} 9.4^{\circ}$ to $\mathrm{R} 17.6^{\circ}$. Owls 7,9 , 14 , and 15 , which had prisms removed at ages ranging from 103 to $182 \mathrm{~d}$, recovered accurate sound localization after restoration of normal vision (Fig. 4): Their localization errors decreased rapidly and continuously over a period of weeks until the accuracy of these birds was within the range exhibited by normal owls (errors of less than $3^{\circ}$ are less than 2 SEM from the average error of normal birds and are therefore considered to be within the normal range; Knudsen et al., 1984a). The age of the oldest bird when it achieved normal accuracy was $190 \mathrm{~d}$ (owl 15). Average rates of adjustment ranged from $0.25^{\circ}$ to $0.80^{\circ}$ d. 


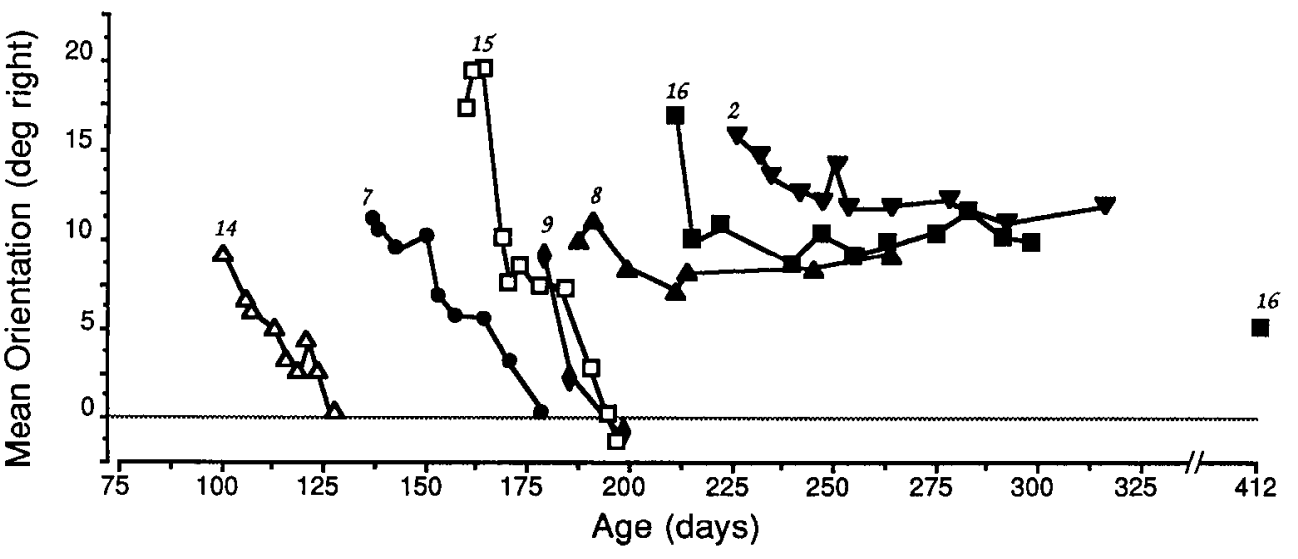

Figure 4. Critical period for visual calibration of sound localization. Sound-localization accuracy (mean head orientation to the auditory stimulus) following prism removal is plotted as a function of age for 7 prism-reared owls. In order from left to right: owls 14 (open triangles), 7 (circles), 15 (open squares), and 9 (diamonds) recovered accurate localization; owls 8 (closed triangles), 16 (closed squares), and 2 (downward triangles) did not.
Owls 2, 8, and 16, which had prisms removed at ages ranging from 190 to $229 \mathrm{~d}$, did not recover accurate sound localization after restoration of normal vision (Fig. 4). The Aud-Vis differences of each owl decreased by from $3^{\circ}$ to $6^{\circ}$ within the first week following prism removal. Subsequently, errors were constant (total change of less than $2^{\circ}$ over $90 \mathrm{~d}$ ). One of these owls (owl 16), which had a sound-localization error of R $11.0^{\circ}$ at 218 $\mathrm{d}$ of age ( $5 \mathrm{~d}$ after prism removal), was tested for the last time at $412 \mathrm{~d}$ of age (189 d after prism removal) and exhibited an error of $\mathrm{R} 5.4^{\circ}$ (square in Fig. 4). The average rate of adjustment for this owl over the 6 month period was $0.03 \%$, a rate that is an order of magnitude slower than that observed among the younger owls. (Average rates of adjustment could not be calculated for owls 2 and 8, becausc thcir total change in localization accuracy by the final day of testing was too small.)

The dramatic decrease in the capacity of owls to adjust sound localization accuracy that occurs by about $200 \mathrm{~d}$ of age is illustrated best by the data from owls 8, 9, and 15 (Fig. 5). Owl 9 wore prisms until $182 \mathrm{~d}$ of age (Fig. $5 A$ ). After prism removal, its sound localization error was $\mathrm{R} 9.4^{\circ}$; by $7 \mathrm{~d}$ later, its error had decreased to R2.3'. In contrast, owl 8 wore prisms until $190 \mathrm{~d}$ of age (Fig. $5 B$ ). After prism removal, its sound localization error was $\mathrm{R} 10.1^{\circ}$; at 77 days later, its error was $\mathrm{R} 9.3^{\circ}$, which was not significantly different from the original error. A difference between the treatments of these 2 birds (in addition to their ages at prism removal) was that owl 8 was subjected to prisms longer than was owl 9 (141 vs. 119 days). However, owl 15 wore prisms longer than either of these birds but had the prisms removed when it was younger (Fig. $5 C$ ). Following prism removal at $159 \mathrm{~d}$ old, owl 15 recovered accurate sound localization. Thus, the capacities of these 3 birds to recover accurate sound localization depended more on age than on the duration of prism experience or on the age at which prisms were attached. These results are corroborated by data from birds subjected to repetitive prism exposures as reported below.

\section{Repetitive visual field displacement}

After an owl has adjusted sound localization once in response to a displaced visual field, and has subsequently recovered accurate localization following prism removal, can it adjust to a second displacement of the visual field later in life? To answer this question, 3 owls $(17,18$, and 19; Table 3$)$ were repeatedly subjected to a displaced visual field.

Owl 17 experienced a rightward displacement of the visual field from 42 to $112 \mathrm{~d}$ old and again from 186 to $228 \mathrm{~d}$ old (Fig. 61 ). In response to the first visual field displacement, the owl adjusted sound localization to the right by $11.9^{\circ}$, an adjustment that is consistent with the sensitive period data (Fig. 3). Following prism removal at $112 \mathrm{~d}$ old, the owl recovered accurate sound localization, as expected from the critical period data (Fig. 4). However, after the prisms were replaced, the owl adjusted sound localization rapidly to the right again, despite being $186 \mathrm{~d}$ old (Fig. 6A). This result was not expected based on the results from owls responding to a displaced visual field for the first time (Fig. 3). Immediately following prism removal at 228 $\mathrm{d}$ old, the owl exhibited a sound localization error of R14.7\%. The owl made a rapid, partial adjustment to $\mathrm{R} 10.1^{\circ}$, but made no further adjustment over the subsequent $80 \mathrm{~d}$ (error $=\mathrm{R} 11.5^{\circ}$ at age $312 \mathrm{~d}$ ). When tested for the final time at $523 \mathrm{~d}$ old, it had

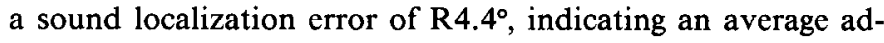
justment rate of $0.02 \%$.

Owl 18 was subjected first to a leftward displacement of the visual field, then to a rightward displacement, then to a second leftward displacement (Fig. 6B). Adjustment to and recovery from the first leftward displacement were as expected from the sensitive and critical period results. However, when subjected for the first time to a rightward visual field displacement at 115 $\mathrm{d}$ old, the owl did not adjust sound localization to the right: when the rightward-deviating prisms were removed after $60 \mathrm{~d}$ of prism experience, the owl still localized auditory stimuli slightly to the left of the source (error $=\mathrm{L} 2.3^{\circ}$ ). This result is consistent with the sensitive period data (Fig. 3) but contrasts sharply with the results from owl 17 , which adjusted to the right at a similar age after having adjusted to the right once before.

To test the capacity of owl 18 to adjust sound localization in the same direction as it had the first time, we subjected the bird

Table 2. Owls used to define the critical period

\begin{tabular}{|c|c|c|c|c|c|}
\hline \multicolumn{2}{|c|}{ Owl } & \multirow{2}{*}{$\begin{array}{l}\text { Prism } \\
\text { strength } \\
\text { (deg. right) }\end{array}$} & \multirow{2}{*}{$\begin{array}{l}\text { Prisms } \\
\text { on } \\
\text { (age in } \\
\text { days) }\end{array}$} & \multirow{2}{*}{$\begin{array}{l}\text { Prisms } \\
\text { off } \\
\text { (age in } \\
\text { days) }\end{array}$} & \multirow{2}{*}{$\begin{array}{l}\text { Duration } \\
\text { of } \\
\text { exposure } \\
\text { (days) }\end{array}$} \\
\hline No. & Identity & & & & \\
\hline 14 & $\mathrm{Ma}$ & 11 & 12 & 103 & 91 \\
\hline 7 & Go & 23 & 35 & 140 & 105 \\
\hline 15 & $\mathrm{Fi}$ & 34 & 12 & 159 & 147 \\
\hline 9 & Or & 23 & 63 & 182 & 119 \\
\hline 8 & Wi & 23 & 49 & 190 & 141 \\
\hline 16 & Mi & 34 & 12 & 214 & 202 \\
\hline 2 & Is & 23 & 10 & 229 & 219 \\
\hline
\end{tabular}


Figure 5. Auditory localization by prism-rcarcd owls following prism rcmoval. The bars at left represent the prism experience of each of 3 owls. At right are shown orientation responses to an auditory stimulus (circles) plotted in coordinates of space relative to the location of the sound source. $A$, Owl 9 had an initial error of $\mathrm{R} 9.4^{\circ}$ following prism removal and adjusted this error completely within $20 \mathrm{~d}$. $B$, Owl 8 , which wore prisms until an older age than did owl 9, had an initial error of R10.1 following prism removal but did not adjust completely even after $77 \mathrm{~d}$ of normal vision. $C$, Owl 15 , which worc prisms the longest of all 3 owls, but was younger when they were removed, had an initial error of $\mathrm{R} 17.6^{\circ}$ following prism removal and adjusted this large error completely within $40 \mathrm{~d}$.
A

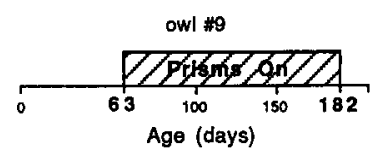

B

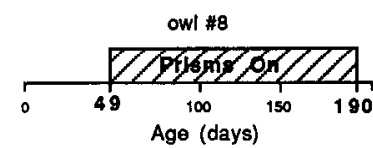

c

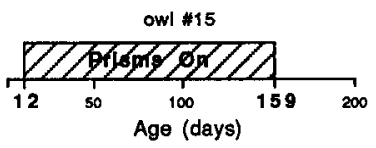

Prisms Off
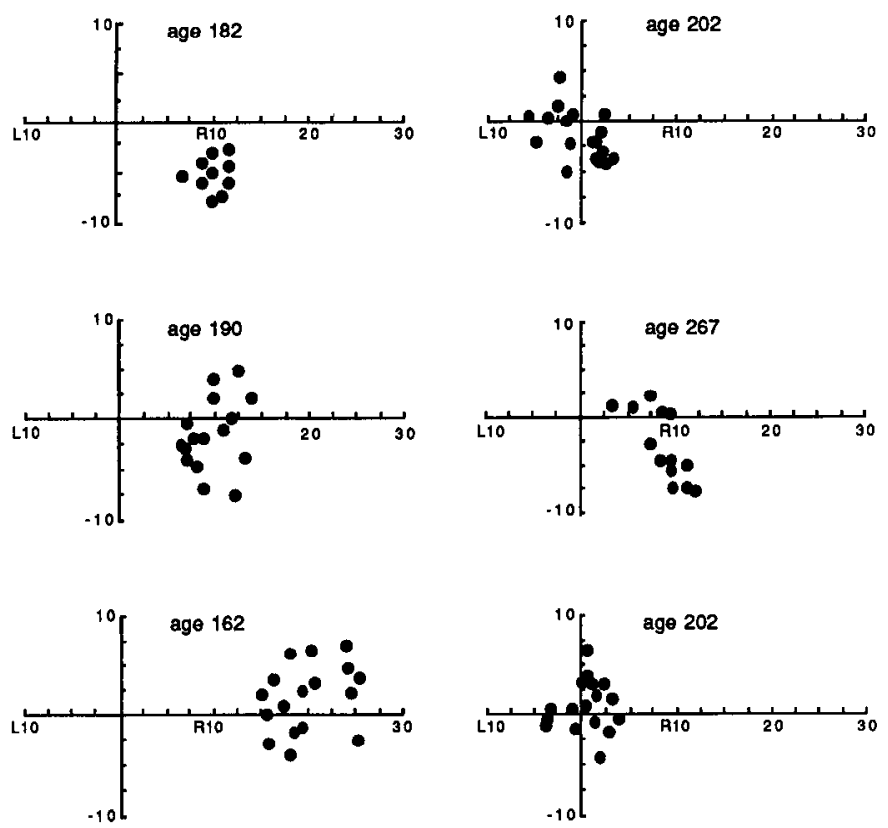

to a second leftward displacement at $181 \mathrm{~d}$ of age (Fig. $6 B$ ). After $64 \mathrm{~d}$ of experience with the $23^{\circ}$ leftward visual displacement, the owl had altered sound localization from $\mathrm{L} 2.3^{\circ}$ to $\mathrm{L} 8.0^{\circ}$. Following removal of the prisms at $246 \mathrm{~d}$ old, the owl maintained this error for as long as it was tested (68 d). Thus, at least up to about $180 \mathrm{~d}$ of age, owl 18 was capable of adjusting sound localization in the same direction as it had during its first prism experience but was not capable of adjusting in the opposite direction.

The treatment of the third bird (owl 19) was essentially a mirror image of the treatment of owl 18 described above. Owl 19 was subjected to a rightward, then to a leftward $\left(34^{\circ}\right)$, and then to a second rightward displacement of the visual field (Fig. $6 C)$. The data from owl 19 were consistent with those from owl 18: Owl 19 adjusted sound localization to the right (R9.9 $)$ in response to the initial righward displacement, did not adjust (L0.8) in response to the leftward displacement, but did adjust again to the right $\left(\mathrm{R} 12.8^{\circ}\right)$ in response to the second rightward displacement. During the second exposure to a rightward displacement, which lasted from 148 until 227 d of age, owl 19 apparently stopped adjusting at about $177 \mathrm{~d}$ of age, leaving a residual $8^{\circ}$ auditory-visual localization discrepancy.

To summarize, 2 owls showed no capacity to adjust sound localization in a new direction once they were beyond the sensitive period, as defined by the results from single-exposure experiments (Fig. 3). In contrast, all 3 owls were capable of adjusting sound localization again in the same direction as they had when they were babies, up to an age that was similar to the critical period, as defined by the results from single-exposure experiments (Figs. 6, 7). In addition, these data confirm the conclusion made in the previous section that the capacity to recover accurate sound localization depends much more on the age of the animal than it does on the duration of prism experience or on the age when prism experience began.

\section{Discussion}

This Discussion is in 3 parts. First, we interpret the results and consider their implications for the mechanisms underlying the calibration of sound localization. Second, the characteristics of adjustment to displaced vision are compared with those of ad-

Table 3. Owls subjected to repeated exposures to displacing prisms

\begin{tabular}{|c|c|c|c|c|c|c|c|c|}
\hline \multirow{2}{*}{\multicolumn{2}{|c|}{ Owl }} & \multirow[b]{2}{*}{$\begin{array}{l}\text { Exposure } \\
\text { (order) }\end{array}$} & \multirow{2}{*}{$\begin{array}{l}\text { Prism } \\
\text { strength } \\
\text { (deg.) }\end{array}$} & \multirow{2}{*}{$\begin{array}{l}\text { Prism on } \\
\text { (age in } \\
\text { days) }\end{array}$} & \multirow{2}{*}{$\begin{array}{l}\text { Prism off } \\
\text { (age in } \\
\text { days) }\end{array}$} & \multicolumn{3}{|l|}{ Prisms off } \\
\hline & Identity & & & & & $\begin{array}{l}\text { A-V difference } \\
\text { (deg.) }\end{array}$ & \pm & $\begin{array}{l}\text { auditory SD } \\
\text { (deg.) }\end{array}$ \\
\hline \multirow[t]{2}{*}{17} & $\mathrm{Bi}$ & 1 & $\mathrm{R} 23$ & 42 & 112 & R 11.9 & \pm & 1.6 \\
\hline & & 2 & $\mathrm{R} 23$ & 186 & 228 & R 14.7 & \pm & 3.6 \\
\hline \multirow[t]{3}{*}{18} & Ds & 1 & $\mathrm{~L} 23$ & 15 & 96 & L 20.3 & \pm & 2.9 \\
\hline & & 2 & $\mathrm{R} 23$ & 115 & 175 & L 2.3 & \pm & 2.7 \\
\hline & & 3 & L23 & 183 & 246 & L 8.0 & \pm & 2.5 \\
\hline \multirow[t]{3}{*}{19} & $\mathrm{Fu}$ & 1 & R23 & 28 & 82 & R 9.9 & \pm & 1.3 \\
\hline & & 2 & L34 & 95 & 143 & L 0.8 & \pm & 2.6 \\
\hline & & 3 & $\mathrm{R} 23$ & 148 & 227 & R 12.8 & \pm & 1.7 \\
\hline
\end{tabular}


justment to monaural hearing impairment. Finally, principles revealed by the data are generalized to other systems.

\section{Calibration of sound localization during development}

Orientation behavior by baby barn owls indicates that neural connectivity supporting crude sound localization is established by innate developmental mechanisms (Knudsen et al., 1984a). Early experience increases the accuracy and precision of sound localization by shaping this connectivity based on discrepancies between visual and auditory localization. Normally, visual and auditory localization agree, and this shaping process simply finetunes the calibration of auditory cue values to take into account idiosyncrasies caused, for example, by the shape or size of the individual's head and ears.

Displacing prisms, by creating exceptionally large visual-auditory localization discrepancies, test the limits of the shaping process. If exposure to displacing prisms begins by $21 \mathrm{~d}$ of age, which is about a week after the eyelids and ear canals first open (Knudsen et al., 1984a), maximal adjustment in sound localization is about $20^{\circ}$ (Knudsen and Knudsen, 1989b). The capacity for adjustment to displaced vision decreases gradually as the animal ages, and by $110 \mathrm{~d}$ of age the range of adjustment to novel displacements of the visual field is approximately the same as that of an adult (Fig. $3 B$ ).

The closing of the sensitive period by approximately $110 \mathrm{~d}$ of age is indicated by 3 lines of evidence. First, linear regression analysis of the data from the 10 young owls in Fig. $3 B$, which plots the decrease in auditory adjustment with age when prisms were attached, yields an $r^{2}$ value of 0.84 and predicts an induced localization error of $3^{\circ}$ for birds $109 \mathrm{~d}$ old, about the age of owl 13 when its prisms were attached (Table 1). Second, owls 18 and 19 made no measureable adjustment of sound localization in response to displacement of the visual field in a novel direction beginning at 115 and $95 \mathrm{~d}$, respectively (Table 3). Third, in a previous study (Knudsen and Knudsen, 1985), prismatic displacement of the visual field induced sound-localization errors of less than $2.5^{\circ}$ in the direction of the visual displacement in 2 owls (numbers 8 and 9) aged 96 and $110 \mathrm{~d}$, respectively. Thus, by $110 \mathrm{~d}$ of age, adjustment to a novel direction of visual field displacement seems to be restricted to the adult range.

The critical period (when persistent associations are being shaped) remains open after the sensitive period closes. During this interim period, which for barn owls is from 110 to $200 \mathrm{~d}$ of age, calibration of sound localization occurs within the range of adjustment defined during the sensitive period: Owls that experience only normal vision and hearing during the sensitive period can fine-tune sound localization over a small range, whereas owls that experience abnormal vision, and adjust sound localization accordingly, retain an extended range of adjustment capacity (Fig. 6). However, the extended adjustment range that is retained through the critical period is specific for the range that was used as a consequence of experience. For example, owl 19, which adjusted sound localization to the right of normal during the sensitive period, retained the capacity to adjust to the right but not to the left of normal later in the critical period (Fig. 6C). Thus, adjustment during the sensitive period prevents the normal, progressive restriction in adjustment range only for the direction that was exercised. This result indicates that adjustment of sound localization to the left of normal can be regulated independently of adjustment of sound localization to the right of normal. The same conclusion was drawn for upward and downward adjustments based on the effect of visual field
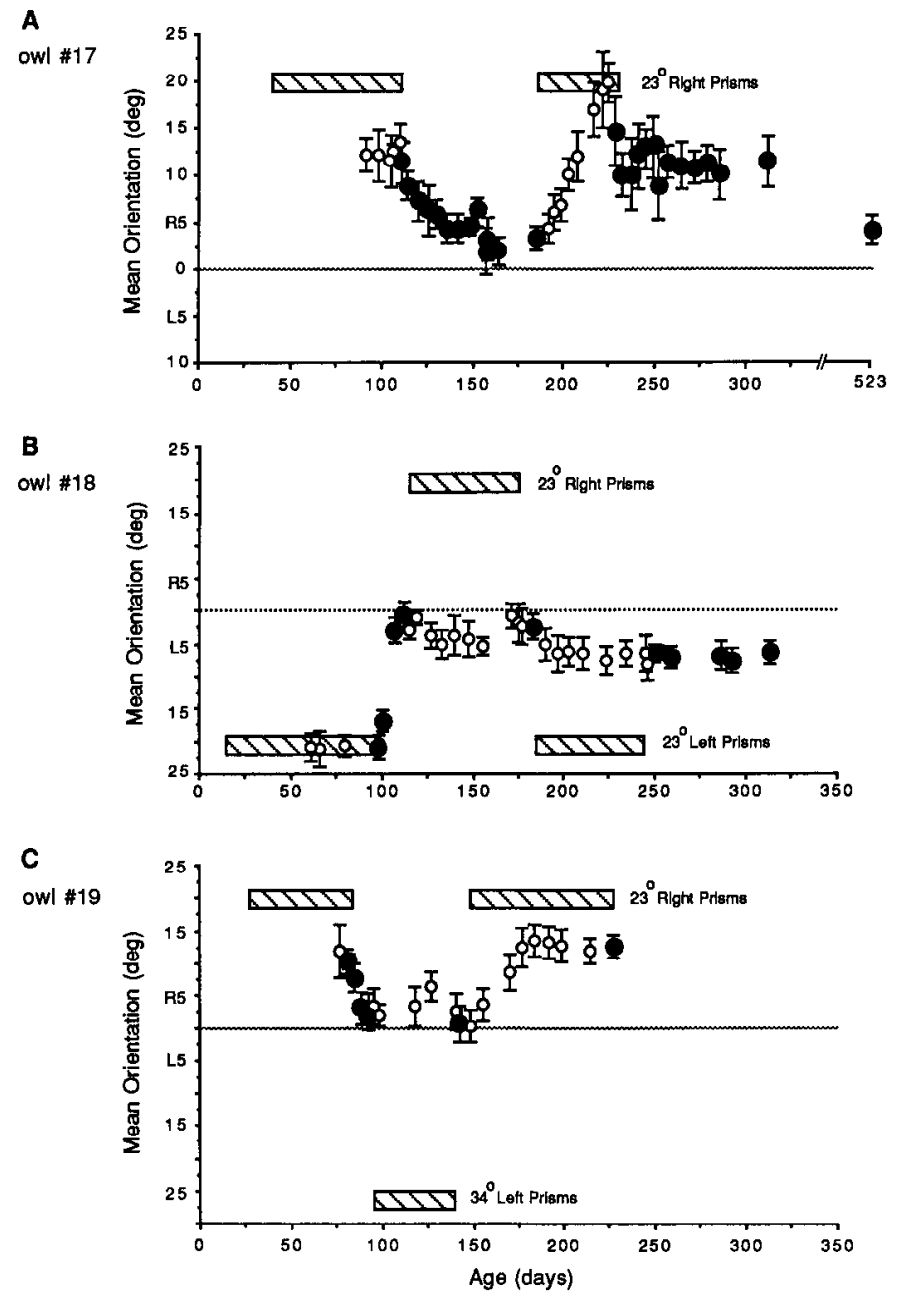

Figure 6. Adjustment of sound localization by owls subjected repetitively to a displaced visual field. Mean and SD head orientation relative to the stimulus source is plotted as a function of age. Open circles represent sound localization with the prisms on; closed circles, sound localization with the prisms removed. The horizontal bars indicate mean orientation to visual stimuli with the prisms on. These values do not equal exactly the optical strength of the prisms. The reason for this discrepancy is not known but possibilities are discussed by Knudsen and Knudsen (1989b). $A$, Owl 17 was subjected twice to a rightward displacement of the visual field. $B$, Owl 18 was subjected to a displacement of the visual field to the left, then to the right, then to the left. $C$, Owl 19 was subjected to a displacement of the visual field to the right, then to the left, and then to the right.

displacement on sound-localization errors induced by early monaural occlusion (Knudsen and Knudsen, 1985).

A predisposition for normal sound localization persists throughout the critical period, regardless of the sensory conditions that an individual experiences. Normal owls do not experience adult correspondences of auditory cue values with visual locations until the eyes are properly positioned in the head, at about $40 \mathrm{~d}$ of age (Knudsen, 1989), and the head and external ears reach full size, at about $45 \mathrm{~d}$ of age (Knudsen et al., 1984a). Obviously, owls that are raised wearing prisms from the day the eyes first open never experience normal adult cue-location correspondences. Nevertheless, when the prisms are removed after the end of the sensitive period (but within the critical period), they adjust sound-localization accuracy back to normal (Fig. 4). The capacity to adjust for the first time to normal cue- 
Figure 7. Adjustment of sound-localization accuracy (mean head orientation) following prism removal for owls subjected repetitively to displacements of the visual field: owl 17 (circles), owl 18 (squares), and owl 19 (triangles). The data are superimposed on the data shown in Figure 4. The pattern of adjustment and the restriction of adjustment after the end of the critical period match well with the data from birds exposed to prisms for one continuous period.

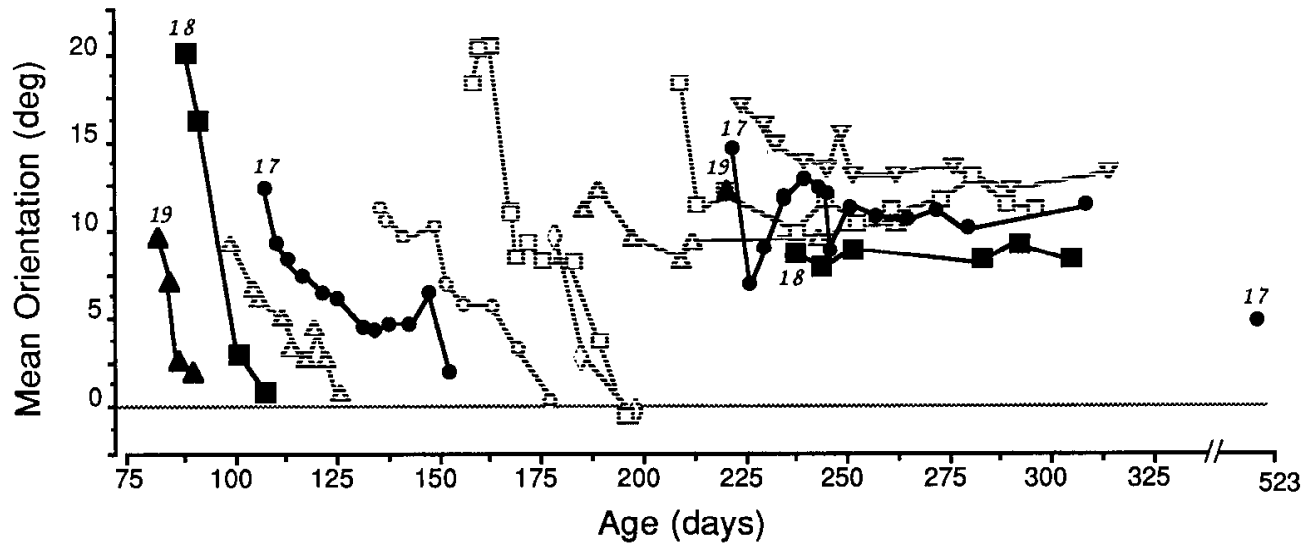

location correspondences at an age when they cannot adjust for the first time to abnormal cue-location correspondences (Fig. 3 vs Fig. 4) indicates an innate predisposition in the auditory system for adjusting to normal correspondences of cue values with locations. Innate predispositions must be based on associations that are predictable from one generation to the next. For example, sound sources located straight ahead give rise to simultaneous sound at the 2 ears, sources located to the left give rise to sound that leads in the left ear, etc. The data suggest that the neural circuitry underlying sound localization is established by innate mechanisms that anticipate these predictable correspondences, but includes the capacity for change should experience dictate otherwise.

The end of the critical period is characterized by a rather sudden and dramatic decrease in the ability to make large adjustments in sound localization (Fig. 4). Cue-location associations seem to crystallize in whatever pattern they happen to be in at the time the period closes: Owls with sound-localization errors maintain those errors despite restoration of normal vision (Fig. 4), and owls that are in the process of adjusting sound localization stop adjusting (owls 18 and 19, Fig. 6). The age at which the critical period closes varies somewhat among individuals. Owl 19 stopped adjusting at $177 \mathrm{~d}$ old, whereas owl 17 continued to adjust up to $225 \mathrm{~d}$ old (Fig. 6). All of the data are consistent with the critical period closing at $200 \pm 25 \mathrm{~d}$ of age (Fig. 4). This is approximately the age at which barn owls reach sexual maturity and begin their first breeding cycles (personal observation).

After the critical period has ended, owls retain the capacity to make small adjustments in sound localization. Adult owls that have been raised normally adjust sound localization by up to $3^{\circ}$ over a period of days when subjected to a displaced visual field or to abnormal auditory cues (Fig. 3; Knudsen et al., 1984a). Adult owls that have a sound localization error due to abnormal visual experience during the sensitive period also make partial adjustments within a few days after restoration of normal vision (Fig. 4). The process that underlies these small adjustments is not limited to a critical period and operates throughout life to fine-tune sound-localization accuracy.

\section{Comparison with adjustment to monaural occlusion}

Previous research has demonstrated that young barn owls adjust sound localization in response to chronic monaural occlusion (Knudsen et al., 1984a, b; Knudsen and Knudsen, 1986). Monaural occlusion creates sound-localization errors by changing the cue values that correspond with any given source location. Because occlusion alters the intensity and timing of different frequencies differently, auditory space is not just displaced, but is disrupled as well. The task under these conditions is to use vision, and perhaps other sources of spatial information, to assign abnormal combinations of cue values to appropriate locations in space. In contrast, prisms cause a relatively coherent displacement of visual space while leaving auditory cues essentially unchanged. The task under these conditions is to assign normal ranges and combinations of cue values to abnormal locations in space.

Although the conditions imposed by monaural occlusion and by prismatic displacement of the visual field are quite different, the adjustments of sound localization that they bring about are similar in some respects. (1) In both cases, sound localization is adjusted gradually, indicating that the interpretation of cue values does not switch abruptly from one location to another, but changes smoothly along a spatial continuum. (2) Adjustments under both conditions are subject to sensitive and critical periods: highly abnormal associations of cue values with locations are formed only during a relatively early period in life, and the capacity for major adjustment of any kind is limited to the first $200 \mathrm{~d}$ of age (Fig. 4; Knudsen et al., 1984b).

Despite these similarities, quantitative and qualitative differences in the adjustment to monaural occlusion and to displacing prisms suggest that the underlying neuronal mechanisms are different (Knudsen et al., 1984a, b). (1) In response to monaural occlusion, adjustment appears to be all or nothing, whereas in response to prisms, adjustment can be partial (Figs. 1-3). (2) The sensitive period for monaural occlusion ends rather abruptly at about $60 \mathrm{~d}$ of age, whereas the sensitive period for displaced vision closes gradually and ends at about $110 \mathrm{~d}$ of age (Fig. $3 B$ ). (3) Adjustment in response to monaural occlusion during the sensitive period does not enable the animal to adjust again to occlusion of the same ear later in the critical period, whereas adjustment in response to prisms preserves the capacity for making a similar adjustment later in the critical period (Fig. 6). (4) Normal experience early in the critical period prolongs the critical period for adjustment of a sound-localization error induced by monaural occlusion, but not one induced by prisms (Fig. 6). (5) The rate of recovery of sound-localization accuracy following removal of an earplug decreases gradually with age as the critical period draws to a close, whereas the rate of recovery following prism removal does not change with age within the critical period (Figs. 4, 7). 
We believe that these differences in the properties of adjustment result from different neuronal substrates being affected by the 2 experimental conditions. Apparent differences could have resulted from differences in the magnitude of the impairment and not from the nature of the impairment, particularly in the case of monaural occlusion, where the effectiveness and constancy of the earplug could not be controlled precisely. Although such a possibility exists, the properties described for adjustment to monaural occlusion held for a wide range of occlusion strengths (as indicated by the sizes of induced localization errors; Knudsen et al., 1984a, b), the properties described for adjustment to visual field displacement held for a wide range of prism strengths, and the sound localization errors induced using either technique were of comparable size. Thereforc, we conclude that the differences are real.

Neural correlates of adjustment to monaural occlusion have been found early in the ascending auditory pathway, by the level of the midbrain: The tuning of neurons in the optic tectum for sound source location changes in parallel with changes in soundlocalization accuracy (Knudsen, 1985). It will be important to determine whether prism-rearing, which imposes such different sensory conditions on the developing brain, induces comparable changes in neuronal spatial tuning and where in the brain the changes occur.

\section{Comparison with other systems}

Analogies exist between visual calibration of sound localization and the development of other functional systems that are shaped by experience such as those subserving language, speech, form vision (amblyopia), stereopsis, etc. (for review, see Rauschecker and Marler, 1987). Space limitations restrict our discussion to a brief comparison with 2 of the more familiar systems: (1) binocular representation in the primary visual cortex of mammals and (2) birdsong. To avoid confusion when making comparisons, the concepts of "sensitive period" and of "critical period" must be clear. In this study, a sensitive period is defined as a limited period in development when exposure to abnormal conditions leads to functional changes that are beyond the range of change exhibited by adults (i.e., causes the primordial state to develop into an abnormal state); a critical period is defined as a period when exposure to normal conditions enables the development of normal function (i.e., causes the primordial state to develop into a normal state). These periods are determined using different experimental strategies by exposing the system to abnormal versus to normal conditions, respectively.

Ideally, in determining these periods, all relevant experience should be eliminated except during the exposure period. Experimentally, this is impossible to achieve since even total deprivation is experience of a kind. Fortunately, the critical period for visual calibration of sound localization appears to be unaffected by the system having adapted to prior sensory conditions (Figs. 5-7) and, therefore, is likely to be equivalent to the critical period as it would be defined under ideal conditions.

In some literature, the concepts of sensitive and critical periods (and the terms) have been used interchangeably. The danger in merging these concepts is that, although in some systems the mechanisms for both may be the same, in others they definitely are not. For example, the sensitive period might be determined by the potential for anatomical modification, while the critical period might be a consequence of stabilization of synaptic gain. Thus, in our search for underlying mechanisms, the distinction between these concepts should be kept in mind.

\section{Binocularity of cortical neurons}

A system that has been studied extensively at the neuronal level is the development of binocular representation in the primary visual cortex of cats and monkeys. Early in ontogeny, apparently all neurons in this part of the cortex can be activated binocularly due in part to a diffuse, overlapping projection of the thalamic inputs representing each eye. As development proceeds, activity modifies the pattern of the projection: In monkeys, afferents from each eye retract approximately equally into nonoverlapping zones in layer IVc. Consequently, neurons in layer IVc become monocularly driven. Binocular neurons arise outside of layer IV $c$ as a result of convergent projections from layer IVc neurons.

During early life, experience with normal binocular vision permits the binocularity of cortical neurons to develop normally. Conversely, abnormal visual experience leads to abnormal patterns of connectivity. Chronic monocular vision causes the majority of cortical neurons to be driven by the experienced eye (Hubel and Wiesel, 1970; Le Vay et al., 1980; Olson and Freeman, 1980; Jones et al., 1984). Misalignment of the eyes, which presumably induces double vision, causes cortical neurons to become monocular with approximately equal numbers of neurons driven by each eye (Hubel and Wiesel, 1965; Van Sluyters and Levitt, 1980). Rearing in total darkness does not alter dramatically the binocularity of responsive neurons but does cause neurons to remain susceptible to the effects of subsequent visual experience (Cynader and Mitchell, 1980; Mower et al., 1985).

The development of binocularity in the primary visual cortex is similar to the development of sound localization in that experience shapes the connectional strengths of inputs during restricted periods in development (Hubel and Wiesel, 1970; LeVay et al., 1978, 1980; Olson and Freeman, 1980; Jones et al., 1984). However, analogies between these systems are limited by a number of fundamental differences. First, in the development of cortical binocular responsiveness, experience regulates the relative strengths of inputs from 2 discrete sources: the left eye versus the right eye. In the development of sound localization, experience guides the selection of appropriate values for each cue from continua of possible cue values. Whereas the balance of left-eye and right-eye inputs to a cortical neuron might be resolved by a competitive process between monocular afferents, the selection of appropriate cue values for sound localization must involve an instructive process. Second, the ocular dominance of cortical neurons ranges normally from total dominance of input from one eye to total dominance of input from the other eye. There is no optimal balance of binocular input strengths that all cortical neurons tend toward, nor is there any balance of input strengths that can be identified as being "abnormal" for any given neuron. It is only the distribution of relative connectional strengths across the population of cortical neurons that can be defined as normal or abnormal. Third, cortical neurons tend not to recover normal binocularity when abnormal visual experience lasts more than just a few days, even though vision in both eyes is restored (Wiesel and Hubel, 1965; Blasdel and Pettigrew, 1978; Malach et al., 1984). In most other systems, including sound localization as well as other visual functions, the system is predisposed to recover normal function as long as normal sensory conditions are restored within a critical period (Stryker et al., 1978; Knudsen et al., 1984b; Rauschecker and Marler, 1987). Although in this regard the development of bin- 
ocularity seems to be fundamentally different, this difference probably is due to irreversible effects of monocular deprivation on the input signals. Restoration of vision to both eyes does not restore normal in put to the cortex, unless proper binocular alignment and eye motor coordination are maintained, and signal transmission in the afferent pathways is normal. Disruption of any of these prior functions would prevent the correlation of binocular afferent signals that is required for cortical neurons to recover normal binocularity. Thus, the binocularity of neurons in the cortex depends on prior motor as well as sensory processes, which themselves may be subject to critical periods that end at earlier ages.

\section{Birdsong}

A system that has been studied thoroughly at the behavioral level is the development of birdsong (Konishi, 1985), which shares important properties with the development of speech in humans (Lenneberg, 1967; Marler, 1970). Adult passerine birds communicate using species-specific songs. Baby songbirds learn to recognize the song of their own species, despite being raised in an environment rich in other sounds. Species-specific song may vary from one geographical region to the next; these song variants are referred to as "dialects" (Marler and Tamura, 1962). In nature, the dialect that a bird learns is the one sung by its parents.

The development of song recognition and the development of sound localization are similar in some respects. Under laboratory conditions, naive baby songbirds of some species can select species-specific songs to learn from a large repertoire of songs based solely on acoustic cues. Thus, the neural circuitry that is involved in song recognition is innately predisposed to process sounds containing specific cues that distinguish the song of the species (Konishi, 1985). In some species of songbirds, song learning is restricted to an early period in development. During this period, experience with acceptable song types shapes the neural "template" used for song recognition (Marler, 1976). Exposure only to abnormal song types throughout a sensitive period results in the bird learning to recognize abnormal song (Konishi, 1985), just as continuous exposure of barn owls to a displaced visual field causes them to associate auditory cues with abnormal source locations. Exposure of songbirds to normal song within a critical period results in the bird learning normal song (Konishi, 1985; Eales, 1987). The range of songs that an individual may select from is determined both by its innate predispositions and by its experience during the sensitive pcriod (Immclmann, 1969; Boehner, 1983; Eales, 1987). This is analogous to the influence of innate predisposition and sensory experience during the sensitive period on the range of cue value-location associations that an owl can select from during the critical period for sound localization (Fig. 6).

\section{References}

Blasdel, G. G., and J. D. Pettigrew (1978) Effect of prior visual experience on cortical recovery from the effects of unilateral eyelid suture in kitten. J. Physiol (Lond.) 248: 663-716.

Boehner, J. (1983) Song learning in the zebra finch (Taeniopygia guttata): Selectivity in the choice of a tutor and accuracy of song copies. Anim. Behav. 31: 231-237.

Cynader, M., and D. E. Mitchell (1980) Prolonged sensitivity to monocular deprivation in dark-reared cats. J. Neurophysiol. 4: 10261040.

Eales, L. A. (1987) Song learning in female-raised zebra finches: Another look at the sensitive phase. Anim. Behav. 35: 1356-1365.

Harris, C. S. (1965) Perceptual adaptation to inverted, reversed, and displaced vision. Psychol. Rev. 72: 419-444.
Held, R., and J. Bossom (1961) Neonatal deprivation and adult rearrangement: Complementary techniques for analyzing plastic sensorymotor coordinations. J. Comp. Physiol. Psychol. 54: 33-37.

Hubel, D. H., and T. N. Wiesel (1965) Binocular interaction in striate cortex of kittens reared with artificial squint. J. Neurophysiol. 28: 1041-1059.

Hubel, D. H., and T. N. Wiesel (1970) The period of susceptibility to the physiological effects of unilateral eye closure in kittens. J. Physiol. (Lond.) 206: 419-436.

Immelmann, K. (1969) Song development in the zebra finch and other estrildid finches. In Bird Vocalizations, R. A. Hinde, ed., pp. 61-74, Cambridge U. P., New York.

Jones, K. R., P. D. Spear, and L. Tong (1984) Critical periods for cffects of monocular deprivation: Differences between striate and extrastriate cortex. J. Neurosci. 4: 2543-2552.

Knudsen, E. I. (1985) Experience alters the spatial tuning of auditory units in the optic tectum during a sensitive period in the barn owl. J. Neurosci. 5: 3094-3109.

Knudsen, E. I. (1989) Fused binocular vision is required for development of proper eye alignment in barn owls. Vis. Neurosci. 2: 35-40.

Knudsen, E. I., and P. F. Knudsen (1985) Vision guides the adjustment of auditory localization in young barn owls. Science 230: 545-548.

Knudsen, E. I., and P. F. Knudsen (1986) The sensitive period for auditory localization in barn owls is limited by age, not by experience. J. Neurosci. 6: 1918-1924.

Knudsen, E. I., and P. F. Knudsen (1989a) Visuomotor adaptation to displacing prisms by adult and baby barn owls. J. Neurosci. 9: 32973305.

Knudsen, E. I. and P. F. Knudsen (1989b) Vision calibrates sound localization in developing barn owls. J. Neurosci. 9: 3306-3313.

Knudsen, E. I., G. G. Blasdel, and M. Konishi (1979) Sound localization by the barn owl measured with the search coil technique. J. Comp. Physiol. 133: 1-11.

Knudsen, E. I., S. D. Esterly, and P. F. Knudsen (1984a) Monaural occlusion alters sound localization during a sensitive period in the barn owl. J. Neurosci. 4: 1001-1011.

Knudsen, E. I., P. F. Knudsen, and S. D. Esterly (1984b) A critical period for the recovery of sound localization accuracy following monaural occlusion in the barn owl. J. Neurosci. 4: 1012-1020.

Konishi, M. (1985) Birdsong: From behavior to neuron. Annu. Rev. Neurosci. 8: 125-170.

Lcnncberg, E. H. (1967) Biological Foundations of Language, Wiley, New York.

LeVay, S., M. P. Stryker, and C. J. Shatz (1978) Ocular dominance columns and their development in layer IV of the cats visual cortex: A quantitative study. J. Comp. Neurol. 179: 223-244.

LeVay, S., T. N. Wiesel, and D. H. Hubel (1980) The development of ocular dominance columns in normal and visually deprived monkeys. J. Comp. Neurol. 191: 1-51.

Malach, R., R. Ebert, and R. C. Van Sluyters (1984) Recovery from effects of brief monocular deprivation in the kitten. J. Neurophysiol. 51: 538-551.

Marler, P. (1970) Birdsong and speech development: Could there be parallels? Am. Sci. 58: 669-673

Marler, P. (1976) Sensory templates in species-specific behavior. In Simpler Networks and Behavior, J. Fentress, ed., pp. 314-329, Sinauer, Sunderland, MA.

Marler, P., and M. Tamura (1962) Song dialects in three populations of white-crowned sparrows. Condor 64: 368-377

Mower, G. D., C. J. Caplan, W. G. Christen, and F. H. Duffy (1985) Dark rearing prolongs physiological but not anatomical plasticity of the cat visual cortex. J. Comp. Neurol. 235: 448-466.

Olson, C. R., and R. D. Freeman (1986) Profile of the sensitive period for monocular deprivation in kittens. Exp. Brain Res. 39: 17-21.

Rauschecker, J. P., and P. Marler (1987) Imprinting and Cortical Plasticity, Wiley, New York.

Stryker, M. P., H. Shrek, A. G. Leventhal, and H. V. B. Hirsch (1978) Physiological consequences for the cat's visual cortex of effectively restricting early visual experience with oriented contours. J. Neurophysiol. 41: 896-909.

Van Sluyters, R. C., and F. B. Levitt (1980) Experimental strabismus in the kitten. J. Neurophysiol. 43: 686-699.

Wiesel, T. N., and D. H. Hubel (1965) Extent of recovery from the effects of visual deprivation in kittens. J. Neurophysiol. 28: 10601072 . 